\title{
Induction of Regulatory T Cells and Prolongation of Fully Allogeneic Cardiac Grafts by Herbal Medicine, Shohangekabukuryo-to
}

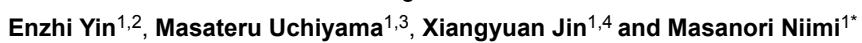

${ }^{1}$ Department of Surgery, Teikyo University, 2-11-1 Kaga, Itabashi-ku, Tokyo 173-8605, Japan

${ }^{2}$ Department of Cardiovascular Surgery, Hospital of Harbin Medical University, 246 Xuefu Road, Nangang, Harbin, Heilongjiang 150086, China

${ }^{3}$ Department of Cardiovascular Surgery, Teikyo University, 2-11-1 Kaga, Itabashi-ku, Tokyo 173-8605, Japan

${ }^{4}$ Department of Thoracic Surgery, the 3rd Affiliated Hospital of Harbin Medical University, 150 Haping Road, Nangang, Harbin, Heilongjiang 150081, China

*Corresponding author: Masanori Niimi, MD, PhD. Department of Surgery, Teikyo University, 2-11-1 Kaga, Itabashi-ku, Tokyo 173-8605, Japan, Tel: +81-3-3964-1228; Fax: +81-3-3962-2128; E-mail: mniimi@zaf.att.ne.jp

Rec date: Aug 24, 2015, Acc date: Sep 26, 2015, Pub date: Oct 3, 2015

Copyright: $\odot 2015$ Yin E, et al. This is an open-access article distributed under the terms of the Creative Commons Attribution License, which permits unrestricted use, distribution, and reproduction in any medium, provided the original author and source are credited.

\begin{abstract}
Objective: Shohangekabukuryo-to (Tsumura Japan [TJ]-21) is well known as an herbal medicine with few side effects to treat vomiting, nausea, acute and chronic gastritis, and hyperemesis of pregnancy in Japan. In this study, we performed fully allogeneic cardiac grafts in mice to investigate the effect of TJ-21 on alloimmune responses.

Methods: $\mathrm{CBA}\left(\mathrm{H} 2^{\mathrm{k}}\right)$ mice underwent transplantation of a $\mathrm{C} 57 \mathrm{BL} / 6\left(\mathrm{H} 2^{\mathrm{b}}\right)$ heart and received oral administration of $0.02,0.2$ and $2 \mathrm{~g} / \mathrm{kg}$ per day of TJ-21 from the day of operation until 7 days afterward. Adoptive transfer study was performed to determine whether regulatory cells were generated. Histologic and cell proliferation studies, flow cytometry analyses and cytokine measurements were also performed.

Results: Compared to untreated CBA mice rejected C57BL/6 hearts acutely (median survival time [MST], 8 days), MST of allografts from TJ-21-treated mice was prolonged (MST, 77 days). Moreover, adoptive transfer of whole splenocytes from TJ-21-treated allograft CBA recipients had prolongation of allograft survival in secondary recipients (MST, 53 days). Flow cytometry study showed TJ-21-treated mice had an increased CD4 ${ }^{+} \mathrm{CD} 25^{+} \mathrm{Foxp}^{+}$ cell population. Cell proliferation showed that interleukin-2 (IL-2) and interferon- $\gamma$ were inhibited in TJ-21-treated mice, whereas IL-4 and IL-10 were increased.
\end{abstract}

Conclusions: In summary, TJ-21 could induce hyporesponsiveness of fully MHC-mismatched cardiac allografts and generate regulatory cells.

Keywords: Shohangekabukuryo-to (Xiao-Ban-Xia-Jia-Fu-LingTang); Herbal medicine; Regulatory T cells; Cardiac transplantation; Mouse

\section{Introduction}

Traditional herbal medicines have been firstly used as far back as $2800 \mathrm{BC}[1,2]$. In recent years, herbal medicines are rapidly increasing worldwide $[3,4]$. They have been used to treat a wide variety of diseases, ranging from the common cold to autoimmune diseases [5]. For example, Mao-to (TJ-27) has been used to treat influenza infection [6], Dai-bofu-to (TJ-97) has been used to treat rheumatoid arthritis [7]. In recent studies of our murine model, oral administration of the herbal medicines Tokishakuyaku-san (TJ-23) [8], Sairei-to (TJ-114) [9], or Artemisiae Capillaris Herba [10] was associated with significantly prolonged survival of allogeneic cardiac grafts (median survival times (MSTs) of all groups $>100$ days) and generation of regulatory cells. Based on these findings, we wondered if there were other several herbal medicines could also affect the immune response.

Shohangekabukuryo-to (TJ-21), one of the traditional Japanese herbal medicines, is composed of 3 herbs: Hoelen, Pinelliae Tuber and Zingiberis rhizoma. In Japan, Hoelen and Pinelliae Tuber have been used to treat dizziness and cough, respectively [11]. Zingiberis has also been found useful in treating vomiting [12]. Meanwhile the 3 components mixture (TJ-21) has been widely used to treat vomiting, nausea [13], acute and chronic gastritis, as well as hyperemesis of pregnancy [14], with few side effects. However, no investigations have been done on the effect of TJ-21 on alloimmune responses after transplantation. Therefore, the purpose of this study was to determine the effects of TJ-21 and its components on the alloimmune response in a murine model of cardiac transplantation.

\section{Materials and Methods}

\section{Animals}

Male C57BL/6 $\left(\mathrm{B} 6, \mathrm{H}_{2} \mathrm{~b}\right)$ and $\mathrm{CBA}\left(\mathrm{H} 2^{\mathrm{k}}\right)$ mice that were 8-12 weeks of age were purchased from Sankyo Ltd. (Tokyo, Japan), housed in conventional facilities at the Biomedical Services Unit of Teikyo University, and used in accordance with the guidelines for animal experimentation approved by the Animal Use and Care Committee of Teikyo University (Teikyo 13-023). 
Citation: Yin E, Uchiyama M, Jin X, Niimi M (2015) Induction of Regulatory T Cells and Prolongation of Fully Allogeneic Cardiac Grafts by Herbal Medicine, Shohangekabukuryo-to. Altern Integr Med 4: 198. doi:10.4172/2327-5162.1000198

Page 2 of 6

\section{Heart transplantation}

All transplant procedures were performed with the mice under general anesthesia. Fully vascularized heterotopic hearts from B6 donor were transplanted into $\mathrm{CBA}$ mice by using microsurgical techniques (Figure 1) [15].

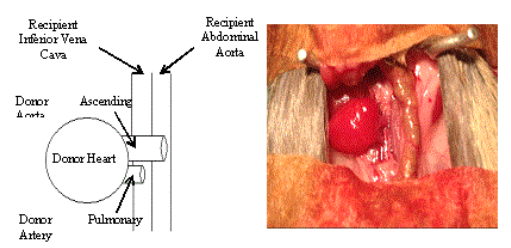

Figure 1: Drawing of anastomoses in the cardiac grafts. The donor ascending aorta is anastomosed to the recipient abdominal aorta and the donor pulmonary artery is sutured end-to-side to the recipient inferior vena cava.
Postoperatively, graft function was assessed daily by palpation for evidence of contraction. Rejection was defined as complete cessation of the heartbeat and confirmed by direct visualization and histologic examination of the graft.

\section{Administration of TJ-21 and Its 3 components}

Naive CBA recipients of a B6 heart were given no treatment, distilled water (control group), or oral administration of 0.02, 0.2 and 2 $\mathrm{g} / \mathrm{kg} /$ day of TJ-21 from the day of transplantation to 7 days afterward.

To identify a specific component of TJ-21 responsible for the immunomodulatory effect, other recipients were given $2 \mathrm{~g} / \mathrm{kg} /$ day of only 1 of the 3 herbal components of TJ-21.

Hoelen, Pinelliae Tuber and Zingiberis Rhizoma comprise 40\%, 48\% and $12 \%$ of TJ-21 respectively; therefore, they were each given in a dose of $0.8 \mathrm{~g} / \mathrm{kg}, 0.96 \mathrm{~g} / \mathrm{kg}$ and $0.24 \mathrm{~g} / \mathrm{kg}$ per day (Table 1 ).

\begin{tabular}{|l|l|l|l|}
\hline Agent administered & Dose (g/kg per day) & Individual STs (days) & MST (days) \\
\hline Hoelen & 2 & $6,16,16,18,18,18,20$ & 18 \\
\hline Pinelliae Tuber & 2 & $7,8,16,18,18,19$ & 17 \\
\hline Zingiberis Rhizoma & 2 & $6,6,10,12,14$ & 10 \\
\hline Hoelen & 0.8 & $7,7,9,25,42$ & 9 \\
\hline Pinelliae Tuber & 0.96 & $6,7,14,17,27$ & 14 \\
\hline Zingiberis Rhizoma & 0.24 & $11,11,24,30,62$ & 14 \\
\hline
\end{tabular}

Table 1: Allograft survival times (ST) in mice given oral administration of components of Shohangekabukuryo-to (TJ-21). MST: Median survival time.

Moreover, we made 3 mixtures in which 1 component of TJ-21 was omitted to investigate whether all 3 components of TJ-21 were essential

in the induction of prolonged survival of cardiac allografts (a different component from each mixture; Table 2).

\begin{tabular}{|l|l|l|l|}
\hline Oral administration (2 g/kg per day) & No. & Individual STs (days) & MST (days) \\
\hline TJ-21 missing Hoelen & 5 & $10,15,15,26,50$ & 15 \\
\hline TJ-21 missing Pinelliae Tuber & 5 & $10,14,23,48,50$ & 23 \\
\hline TJ-21 missing Zingiberis Rhizoma & 5 & $9,13,13,21,>100$ & 13 \\
\hline
\end{tabular}

Table 2: Allograft survival (ST) of administration of 1 component omitted Shohangekabukuryo-to (TJ-21). MST: Median survival time.

All the herbal medicines were dissolved in distilled water and given orally with use of a metal tube (Thomas Scientific, Swedesboro, NJ). The medicines were made as frozen dry powder gifted by Tsumura (Tokyo, Japan).

\section{Adoptive transfer studies}

Adoptive transfer studies were conducted to determine whether regulatory cells were generated after treatment with TJ-21. Accordingly, 30 days after CBA recipients (primary recipients) underwent transplantation of a B6 cardiac allograft and treatment with TJ-21 (2 g/kg/day), splenocytes $\left(5.0 \times 10^{7}\right)$ from primary recipients with functioning allografts were adoptively transferred into naive CBA mice (secondary recipients) through the penile vein. After the adoptive transfer, the secondary recipients underwent transplantation of a $\mathrm{B} 6$ heart, immediately.

\section{Histologic studies of harvested grafts}

Cardiac grafts transplanted into untreated mice and mice given TJ-21 were removed 30 days after transplantation and studied immunohistochemically and histologically. Immunohistochemical and Histologic staining were performed as described previously [16]. Hematoxylin and eosin (HE) staining was assessed by grading with a 
semiquantitative scale for the amount of mononuclear cell infiltration (0, no infiltration; 1 , faint and limited infiltration; 2, moderate infiltration; 3, severe infiltration) $[17,18]$. In immunohistochemical (IHC) study, the number of infiltrating Foxp $3^{+}$cell in TJ-21-treated or untreated mice was counted. All graft heart slides were assessed blindly by unrelated one researcher.

\section{Flow cytometry analysis}

CD4, CD25, and Foxp3 expression in splenocytes was determined by flow cytometry. 30 days after cardiac allograft transplantation, splenocytes from recipients treated with TJ-21, untreated recipients, and naive CBA mice were stained with fluorochrome-conjugated antiCD4 or anti-CD25 monoclonal antibody (mAb) (RM4-5 and PC61, respectively; BD Biosciences, San Jose, CA) or anti-mouse Foxp3 mAb (FJK-16s; eBioscience, San Diego, CA), as well as their isotype controls. The stained cells were analyzed by using a FACS Canto2 system (BD Biosciences).We analyzed stained cells with a FACS Canto2 system (BD Biosciences) to determine the percentage of $\mathrm{CD} 4^{+} \mathrm{CD}_{2} 5^{+}$Foxp $^{+}$ cells in $\mathrm{CD} 4^{+}$cells.

\section{Cell proliferation and cytokines}

In mixed leukocyte culture (MLC) studies [19], the responder cells were splenocytes from naive CBA mice or from untreated or TJ-21treated CBA mice that had undergone transplantation of a B6 heart 14 days earlier. The stimulator cells were B6 (allogeneic) splenocytes treated with $100 \mu \mathrm{g} / \mathrm{mL}$ mitomycin C (Kyowa Hakko, Osaka, Japan) for 30 minutes at $37^{\circ} \mathrm{C}$. The responder cells $\left(2.5 \times 10^{6} / \mathrm{mL}\right)$ were cocultured with the stimulator cells $\left(5.0 \times 10^{6} / \mathrm{mL}\right)$ in complete medium in a humidified $5 \%$ carbon dioxide atmosphere $(\mathrm{CH}-16 \mathrm{M}$; Hitachi, Tokyo, Japan) at $37^{\circ} \mathrm{C}$ in 96 -well, round-bottomed, tissue-culture plates (Iwaki Scitech Division, Tokyo, Japan) for 4 days. Proliferation was assessed by using an enzyme-linked immunosorbent assay (ELISA) for bromodeoxyuridine incorporation (Biotrak, version 2; Amersham, Little Chalfont, UK) according to the manufacturer's instructions [20].

An ELISA was also performed to assess levels of interleukin (IL)-2, IL-4, IL-10, and interferon (IFN)- $\gamma$ in the supernatant of the MLC on day 4. The capture mAb (JES5-2A5), detection mAb (JES5-16E3), and recombinant standard for IL-10 were from BD Biosciences. The capture and detection mAbs for IL-2 (JES6-1A12 and JES6-5H4, respectively), IL-4 (BVD-1D11 and BVD-24G2, respectively), and IFN- $\gamma$ (R4-6A2 and XMG1.2, respectively) were from Caltag Laboratories (Burlingame, CA). Recombinant standards for IL-2, IL-4, and IFN- $\gamma$ were from PeproTech (London, UK).

\section{Statistical analysis}

Cardiac allograft survival in groups of mice was compared by using Mann-Whitney U testing (Graphpad Prism; Graphpad, CA). In the cell proliferation, cytokine, and flow cytometry studies, 2 groups were compared by using unpaired Student t-test or analysis of variance (ANOVA) with Ryan method. $\mathrm{P}<0.05$ was considered significant.

\section{Results}

\section{Survival of cardiac allografts in mice treated with TJ-21 and each component}

CBA mice with no treatment or oral administration of distilled water rejected B6 allografts acutely (median survival times [MSTs], 8 days, Figure 2a). CBA recipients given 2 g/kg/day of TJ-21 had prolonged cardiac allograft survival (MSTs, 77 days, $\mathrm{P}<0.01$ versus untreated and distilled water-treated group, respectively, Figure 2a). 0.2 $\mathrm{g} / \mathrm{kg} /$ day of TJ-21 was less effective in prolongation of grafts survival (MSTs, 13 days, $\mathrm{P}<0.05$ versus distilled water-treated group, Figure $2 \mathrm{a}$ ).

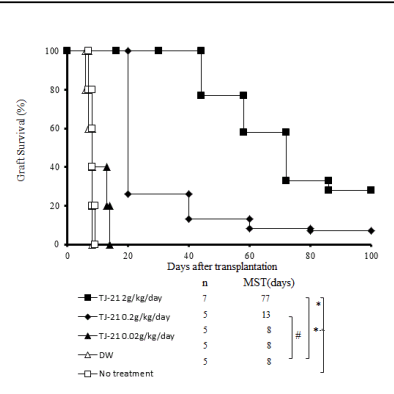

Figure 2a: Cardiac allograft survival and histologic studies. Allograft recipients were either not treated, given distilled water (DW), or treated with $2,0.2,0.02 \mathrm{~g} / \mathrm{kg}$ per day of TJ-21 from the day of transplantation until 7 days afterward. ${ }^{*} \mathrm{p}<0.01$ and ${ }^{*} \mathrm{p}<0.05$ for difference between 2 groups.

The components of TJ-21 induced only modest prolongation on cardiac grafts in mice (Table 1). Moreover, when CBA mice with cardiac grafts were orally administered 1 component missing mixtures, none of the graft survival was prolonged as long as the real TJ-21 (Table 2).

\section{Histologic features of allografts from recipients treated with TJ-21}

Histologic examinations of cardiac allografts obtained 30 days after transplantation showed cell infiltrated but significantly preserved structure with a few myocardial injuries in transplant recipients given TJ-21, whereas allografts from untreated recipients showed severe myocyte damage and edema of the acute rejection process (Figure $2 \mathrm{~b}$ ). Moreover, in each section of HE staining there was a significant difference by grading with a semiquantitative scale [21].

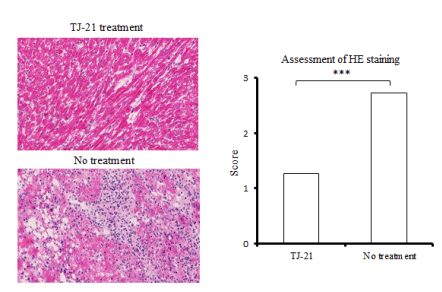

Figure 2b: Histologic studies of harvested cardiac allografts stained with hematoxylin-eosin (HE). The upper left picture shows a representative sample obtained from mice given TJ-21 and the lower left picture shows the sample from untreated mice (magnification $\times 20$ of two pictures). The right graph shows the degree of mononuclear cell infiltration was assessed by grading with semiquantitative scale $(0$, no infiltration; 1 , faint and limited infiltration; 2, moderate infiltration; 3, severe infiltration). ${ }^{* * *} \mathrm{p}<0.001$ for difference between 2 groups. 
Citation: Yin E, Uchiyama M, Jin X, Niimi M (2015) Induction of Regulatory T Cells and Prolongation of Fully Allogeneic Cardiac Grafts by Herbal Medicine, Shohangekabukuryo-to. Altern Integr Med 4: 198. doi:10.4172/2327-5162.1000198

Page 4 of 6

\section{Generation of regulatory cells in mice treated with TJ-21}

In adoptive transfer study, we found that naïve secondary CBA allograft recipients given adoptive transfer of splenocytes from TJ-21 treated CBA recipients 30 days after heart transplantation graft had significantly prolonged survival of $\mathrm{B} 6$ hearts (MSTs, 53 days, $\mathrm{P}<0.01$ versus the transfer of splenocytes from naïve CBA mice, Figure $3 \mathrm{a}$ ).

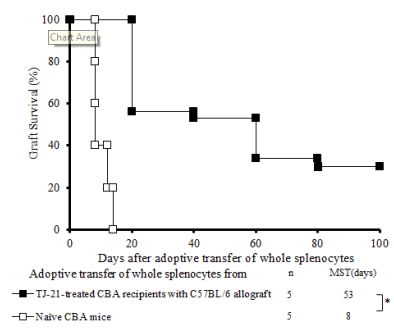

Figure 3a: Evidence of generation of regulatory cells in CBA allograft recipients treated with TJ-21. (A) Cardiac allograft survival after adoptive transfer of whole splenocytes. MST: median survival time; ${ }^{*} \mathrm{p}<0.01$ for difference between 2 groups.

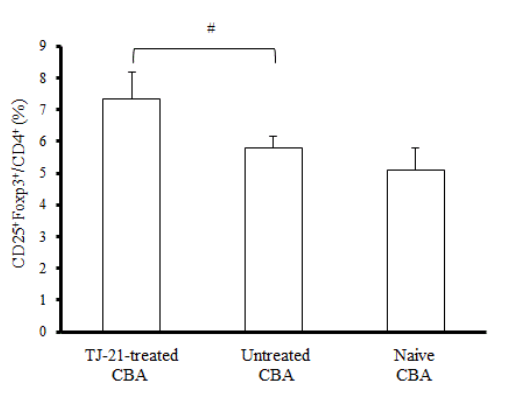

Figure 3b: CD4, CD25, and Foxp3 expression in splenocytes, as determined by flow cytometry. Data are mean \pm SD $(=5$ mice in each group). ${ }^{\#} \mathrm{p}<0.05$ for difference between 2 groups.

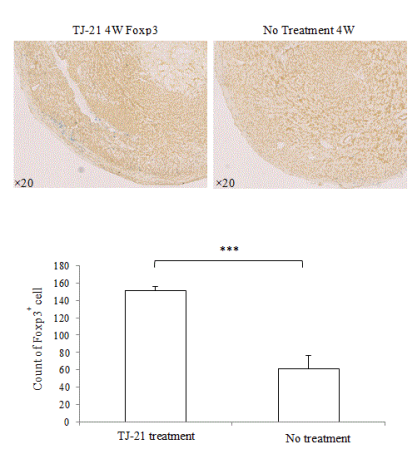

Figure 3c: Infiltration of Foxp $3^{+}$cells in cardiac grafts 30 days after grafting from untreated or TJ-21-treated recipients (magnification $\times 20$ ). The down graph shows the count of infiltrating Foxp $3^{+}$cells in cardiac allografts form untreated or TJ-21-treated recipients. ${ }^{* * *}$ $\mathrm{p}<0.001$ for difference between 2 groups.
In flow cytometry study, the percentage of population of $\mathrm{CD} 25^{+} \mathrm{Foxp}^{+}$cells in $\mathrm{CD} 4^{+}$cells was increased in the spleens of recipients given TJ-21 compared with those of untreated CBA recipients $(\mathrm{P}<0.05$; Figure $3 \mathrm{~b})$. There is no significant difference in the percentage of population of $\mathrm{CD} 4^{+} \mathrm{CD} 25^{+} \mathrm{Foxp}^{+}$cells in $\mathrm{CD} 4^{+}$cells between the naive CBA with and without TJ-21(Figure 3b).

Additionally, IHC study showed that the number of Foxp $3^{+}$cells in cardiac grafts from TJ-21-treated CBA recipients obviously increased more than that in untreated recipients $(\mathrm{P}<0.05$; Figure $3 \mathrm{c})$.

\section{Cell proliferation and cytokine production in mice treated with TJ-21}

Maximum proliferation of naïve CBA splenocytes (responder cells) against B6 splenocytes (stimulator cells) treated with mitomycin $\mathrm{C}$ occurred on the day of MLC. Proliferation of splenocytes from CBA recipients given $\mathrm{TJ}-21$ was significantly suppressed compared with that of splenocytes from untreated mice $(\mathrm{P}<0.05$, Figure $4 \mathrm{a})$.

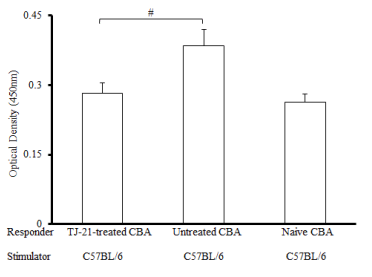

Figure 4a: Evidence of induction of alloproliferative hyporesponsiveness in CBA recipients of allograft treated with TJ-21. Results of cell-proliferation assays in mixed leukocyte cultures (MLCs). The data shown are mean \pm SD values derived from samples from 6 mice in each group. ${ }^{*} \mathrm{p}<0.05$ for difference between 2 groups.

Levels of IL-2 (Figure 4b) and IFN- $\gamma$ (Figure 4c) in splenocytes from mice treated with TJ-21 were significantly lower than those in splenocytes from untreated CBA mice.

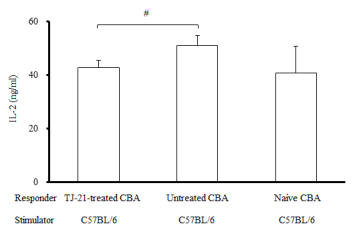

Figure 4b: Levels of cytokines in MLCs. Levels of interleukin (IL)-2 (B) in the MLCs were assessed by enzyme-linked immunosorbent assays. Data are shown as mean \pm SD values derived from samples from 6 mice in each group. ${ }^{*} \mathrm{p}<0.05$ for difference between 2 groups. 


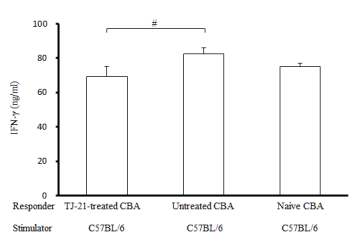

Figure 4c: Levels of cytokines in MLCs. Levels of interleukin interferon- (C), in the MLCs were assessed by enzyme-linked immunosorbent assays. Data are shown as mean $\pm \mathrm{SD}$ values derived from samples from 6 mice in each group. ${ }^{\#} \mathrm{p}<0.05$ for difference between 2 groups.

In contrast, levels of IL-4 (Figure 4d) and IL-10 (Figure 4e) were increased in recipients treated with TJ-21 compared with untreated CBA mice.

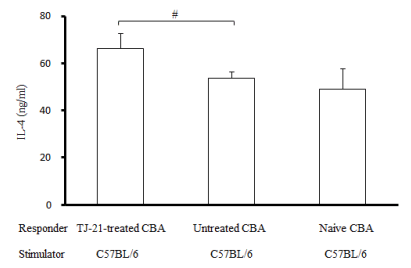

Figure 4d: Levels of cytokines in MLCs. Levels of IL-4 (D) in the MLCs were assessed by enzyme-linked immunosorbent assays. Data are shown as mean \pm SD values derived from samples from 6 mice in each group. ${ }^{*} \mathrm{p}<0.05$ for difference between 2 groups.

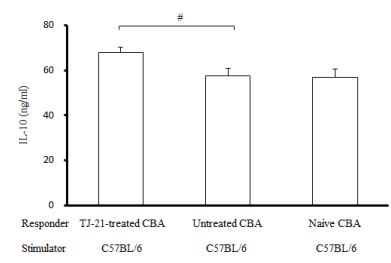

Figure 4e: Levels of cytokines in MLCs. Levels of interleukin IL-10 (E) in the MLCs were assessed by enzyme-linked immunosorbent assays. Data are shown as mean \pm SD values derived from samples from 6 mice in each group. ${ }^{\#} \mathrm{p}<0.05$ for difference between 2 groups.

\section{Discussion}

This study demonstrated that TJ-21 could prolong survival of fully allogeneic cardiac grafts in mice and effect alloimmune responses in our heart transplantation model. There are several mechanisms by which treatment with TJ-21 has induced increased allograft survival in our model. The first mechanism of our research is that TJ-21 induced regulatory cells. Active suppression of regulatory cells has been found to be involved in the mechanisms for induction and maintenance of self-tolerance [22] and prevention of vasculopathy in cardiac allografts $[23,24]$ and unresponsiveness to allografts [25]. Additionally, we have ever submitted many manuscripts about the potential of immunomodulation and immunosuppressive effect on herbal medicines [10,26]. Our adoptive transfer study showed that administration of whole splenocytes from allograft recipients treated with TJ-21 had significantly prolonged survival of their B6 cardiac allograft (Figure 3a). In our current studies, the population of $\mathrm{CD} 4^{+} \mathrm{CD} 25^{+} \mathrm{Foxp}^{+}$cells in the spleens from TJ-21-treated CBA recipients obviously increased in flow cytometry (Figure $3 \mathrm{~b}$ ) and TJ-21-treated recipients clearly had more Foxp $3^{+}$cells than untreated recipients (Figure 3c).Moreover, allo-proliferation of splenocytes from TJ-21-treated CBA recipients was visibly suppressed in MLC (Figure 4a). These data suggest that treatment with TJ-21 generated regulatory cells, including $\mathrm{CD} 4^{+} \mathrm{CD} 25^{+} \mathrm{Foxp} 3^{+}$cells, in primary CBA recipients.

A second possible mechanism for TJ-21 prolonged survival of allogeneic cardiac grafts in mice is that the balance between Th-1 and Th-2 cytokines secretion may affect the regulatory cells' function strongly. In our previous studies, we have demonstrated that inducible regulatory $\mathrm{T}$ cells (Tregs) might enable the change of Th-1 and Th-2 cytokines [27]. Moreover, some studies demonstrated that administration of traditional herbal medicines could change Th- 1 and Th- 2 cytokines in mice $[28,29]$. In our current study, a distinguished increase of Th-2 cytokine (IL-4 and IL-10) and a decrease of Th-1 cytokine (IL-2 and IFN- $\gamma$ ) were detected in the TJ-21-treated CBA recipients (Figures $4 \mathrm{~b}-4 \mathrm{e}$ ), suggesting that administration of TJ-21 might generate regulatory cells by $\mathrm{Th}-1 / \mathrm{Th}-2$ cytokine changes.

The third possible mechanism is that TJ-21 treatment resulted in suppression of the infiltration and proliferation of leukocytes. Our histologic studies of allografts obtained from TJ-21-treated recipients showed much less leukocyte infiltration and maintenance of myocardial structure than those from no treated recipients (Figure 2b). Moreover, our MLC and ELISA studies showed that TJ-21-treated allograft recipients showed down-regulation of leukocyte proliferation and the production of IL-2, IFN- $\gamma$. IFN- $\gamma$ has been found to be one of key effectors in cardiac graft arteriosclerosis and participate in cellmediated vascular injury which could cause indirect myocyte injury [30,31]. According to this mechanism, TJ-21 would have protected allografts against immune injury.

Interestingly, we found that no single component of TJ-21, used either alone or in an increased dose, prolonged allograft MSTs (Table 1) to the extent that TJ-21 itself did. Moreover, no TJ-21 formula that was missing one of the 3 components increased MSTs (Table 2) as much as TJ-21 did. Only the complete TJ-21 combination of all 3 components induced significant prolongation of allograft survival. Actually, our previous investigations about Tokishakuyaku-san (TJ-23) and Sairei-to (TJ-114) had the similar results $[8,32]$. These results indicate that interaction among the components was significant in prolonging allograft MSTs. A traditional assumption in herbal medicine, herbal formulas have an overall effect that is different from the effects of their components, could explain these possibilities [32].

\section{Conclusion}

From this finding, we demonstrated that treatment with TJ-21 induced generated regulatory cells and prolonged survival of fully allogeneic cardiac grafts in mice.

\section{Acknowledgments}

The authors thank Professor Kenjiro Matsuno and Mr. Hisashi Ueta, Department of Anatomy (Macro), Dokkyo University, Tochigi, Japan and Professor Kouji Matsushima and Dr. Satoshi Ueha, Department of 
Molecular Preventive Medicine and SORST, Graduate School of Medicine, The University of Tokyo, Tokyo, Japan for technical assistance with the immunohistochemistry studies. Also, the authors thank Professor Toshio Nakaki and Dr. Nobuko Matsumura, Department of Pharmacology, Teikyo University, Tokyo, Japan for the assistant of histologic study.

\section{References}

1. Braquet P, Hosford D (1991) Ethnopharmacology and the development of natural PAF antagonists as therapeutic agents. J Ethnopharmacol 32: 135-139.

2. Jie YH, Cammisuli S, Baggiolini M (1984) Immunomodulatory effects of Panax Ginseng C.A. Meyer in the mouse. Agents Actions 15: 386-391.

3. [No authors listed] (1996) Complementary medicine is booming worldwide. BMJ 313: 131-133.

4. Eisenberg DM, Davis RB, Ettner SL, Appel S, Wilkey S, et al. (1998) Trends in alternative medicine use in the United States, 1990-1997: results of a follow-up national survey. JAMA 280: 1569-1575.

5. Borchers AT, Hackman RM, Keen CL, Stern JS, Gershwin ME (1997) Complementary medicine: a review of immunomodulatory effects of Chinese herbal medicines. Am J Clin Nutr 66: 1303-1312.

6. Kubo T, Nishimura H (2007) Antipyretic effect of Mao-to, a Japanese herbal medicine, for treatment of type A influenza infection in children. Phytomedicine 14: 96-101.

7. Ono Y, Ogihara Y, Saijo S, Iwakura Y, Inoue M (2003) Evaluation of Kampo medicines used to treat rheumatoid arthritis in collagen-induced arthritic and pX transgenic mice. Mod Rheumatol 13: 50-56.

8. Zhang Q, Uchiyama M, Jin X, Iwami D, Shirasugi N, et al. (2011) Induction of regulatory $\mathrm{T}$ cells and prolongation of survival of fully allogeneic cardiac grafts by administration of Tokishakuyaku-san in mice. Surgery 150: 923-933.

9. Zhang Q, Iwami D, Aramaki O, Yakubo S, Nishimura K, et al. (2009) Prolonged survival of fully mismatched cardiac allografts and generation of regulatory cells by Sairei-to, a Japanese herbal medicine. Transplantation 87: 1787-1791.

10. Jin XY, Uchiyama M, Zhang Q, Hirai T, Niimi (2012) MInchingorei-san (TJ-117) and Artemisiae Capillaris Herba induced prolonged survival of fully mismatched cardiac allografts and generated regulatory cells in mice. Evidence-Based Complementary and Alternative Medicine Maki T, Takahashi K, Shibata S (1987) An anti-emetic principle of Pinellia ternata tuber. Planta Med 53: 410-414.

11. Kawai T, Kinoshita K, Koyama K, Takahashi K (1994) Anti-emetic principles of Magnolia obovata bark and Zingiber officinale rhizome. Planta Med 60: 17-20.

12. Katagirl F, Itoh H, Takeyama M (2004) Effect of Sho-hange-ka-bukuryoto on Gastrointestinal Peptide Concentrations in the Plasma of Healthy Human Subjects. Biological \& Pharmaceutical Bulletin 27: 1674-1678.

13. Katagirl F, Shiga T, Sato Y, Inoue S, Itoh H, et al. (2004) Comparison of the effects of cytoprotective drugs on human plasma adrenocorticotropic hormone and cortisol levels with continual stress exposure. Biological \& Pharmaceutical Bulletin 27: 1679-1682.

14. Niimi M (2001) The technique for heterotopic cardiac transplantation in mice: experience of 3000 operations by one surgeon. J Heart Lung Transplant 20: 1123-1128.

15. Uchiyama M, Jin XY, Zhang Q, Hirai T, Bashuda H, et al. (2012) Danazol induces prolonged survival of fully allogeneic cardiac grafts and maintains the generation of regulatory CD4+ cells in mice. Transplant International 25: 357-365.
16. Berry GJ, Brunt EM, Chamberlain D, Hruban RH, Sibley RK, et al. (1990) A working formulation for the standardization of nomenclature in the diagnosis of heart and lung rejection: heart rejection study group. Journal of Heart Transplantation 9: 587-593.

17. Stewart S, Winters GL, Fishbein MC, Tazelaar HD, Kobashigawa J, et al. (2005) Revision of the 1990 working formulation for the standardization of nomenclature in the diagnosis of heart rejection. J Heart Lung Transplant 24: 1710-1720.

18. Akiyama $\mathrm{Y}$, Shirasugi N, Uchida N, Matsumoto K, Kitajima M, et al. (2002) B7/CTLA4 pathway is essential for generating regulatory cells after intratracheal delivery of alloantigen in mice. Transplantation 74: 732-738.

19. Perros P, Weightman DR (1991) Measurement of cell proliferation by enzyme-linked immunosorbent assay (ELISA) using a monoclonal antibody to bromodeoxyuridine. Cell Prolif 24: 517-523.

20. Uchiyama M, Jin X, Matsuda H, Bashuda H, Imazuru T, et al. (2014) An agonistic anti-BTLA $\mathrm{mAb}(3 \mathrm{C} 10)$ induced generation of IL-10-dependent regulatory $\mathrm{CD} 4+\mathrm{T}$ cells and prolongation of murine cardiac allograft. Transplantation 97: 301-309.

21. Itoh M, Takahashi T, Sakaguchi N, Kuniyasu Y, Shimizu J, et al. (1999) Thymus and autoimmunity: production of $\mathrm{CD} 25+\mathrm{CD} 4+$ naturally anergic and suppressive $\mathrm{T}$ cells as a key function of the thymus in maintaining immunologic self-tolerance. J Immunol 162: 5317-5326.

22. King CL, Devitt JJ, Lee TD, Hancock Friesen CL (2010) Neutrophil mediated smooth muscle cell loss precedes allograft vasculopathy. J Cardiothorac Surg 5: 52.

23. Devitt JJ, King CL, Lee TD, Hancock Friesen CL (2011) Early innate immune events induced by prolonged cold ischemia exacerbate allograft vasculopathy. J Cardiothorac Surg 6: 2.

24. Wood KJ, Sakaguchi S (2003) Regulatory T cells in transplantation tolerance. Nat Rev Immunol 3: 199-210.

25. Jin XY, Yu L, Uchiyama M, Yin EZ, Harada T, et al. (2014) Combination of Paeoniae Radix and Cnidii Rhizoma prolonged survival of fully mismatched cardiac allografts and generated regulatory cells in mice. Evidence-Based Complementary and Alternative Medicine

26. Uchiyama M, Jin XY, Zhang Q, Hirai T, Amano A, et al. (2012) Auditory stimulation of opera music induced prolongation of murine cardiac allograft survival and maintained generation of regulatory CD4+CD25+ cells. Journal of Cardiothoracic Surgery 7:26.

27. Sun Y, Cai TT, Shen Y, Zhou XB, Chen T, et al. (2009) Si-Ni-San, a traditional Chinese prescription, and its active ingredient glycyrrhizin ameliorate experimental colitis through regulating cytokine balance. Int Immunopharmacol 9: 1437-1443.

28. Watanabe T, Yamamoto T, Yoshida M, Fujiwara K, Kageyama-Yahara N, et al. (2010) The traditional herbal medicine saireito exerts its inhibitory effect on murine oxazolone-induced colitis via the induction of Th1polarized immune responses in the mucosal immune system of the colon. Int Arch Allergy Immunol 151: 98-106.

29. Barry WH (1994) Mechanisms of immune-mediated myocyte injury. Circulation 89: 2421-2432.

30. Tellides G, Pober JS (2007) Interferon-gamma axis in graft arteriosclerosis. Circ Res 100: 622-632.

31. Zhang Q, Jin X, Uchiyama M, Yakubo S, Niimi M (2010) Impact of saireito and its individual constituents on cardiac allograft survival. J Heart Lung Transplant 29: 818-820.

32. Ikegami F, Sumino M, Fujii Y, Akiba T, Satoh T (2006) Pharmacology and toxicology of Bupleurum root-containing Kampo medicines in clinical use. Hum Exp Toxicol 25: 481-494. 